\title{
Promoting Resilience and Psychological Well-Being in Vulnerable Life Stages
}

\author{
Ernesto Caffo ${ }^{a}$ Carlotta Belaise $^{b}$ Barbara Forresi $^{a}$ \\ a Mother and Child Department, University of Modena and Reggio Emilia, Modena, and \\ ${ }^{b}$ Department of Psychology, University of Bologna, Bologna, Italy
}

Mental health and emotional and psychological wellbeing are fundamental for all children, enabling them to meet their potential, to experience life as meaningful and to be active citizens.

Unfortunately, current estimates indicate that at least one out of every four to five young people in the general population will suffer from at least one mental disorder in any given year [1]. Similar data have been previously reported by WHO, showing that worldwide up to $20 \%$ of children and adolescents suffer from a mental illness with at least mild functional impairment: one adolescent in five has behavioural, cognitive and emotional difficulties and one adolescent in eight suffers from a mental disorder [2]. Comorbidity is very common and can occur at three levels: with other mental disorders, with substance abuse and with chronic diseases [1].

Developmental psychiatric disorders rarely have a spontaneous remission and may cause difficulties in social adaptation or mental disorders in adult life [3-12]. There is evidence that adult mental disorders usually begin during youth $[13,14]$, although they are often first detected later in life [1].

Besides personal suffering, stigma and discrimination, mental disorders may have a high social impact, in terms of treatment and support costs, reduced or lost productivity, and the expenditure of criminal justice (e.g. conduct and behavioural disorders) [15].

Despite these data, only a minority of vulnerable children and adolescents have access to mental health ser- vices, even in high-income countries [16]; the majority of young people with mental health problems are still not getting the help they need. A major reason for this is the worldwide gaps in child and adolescent mental health policy and services well identified by the World Health Organization through its Atlas project [17]. The degree of coverage and quality of mental health services for the youths are generally worse compared with the ones provided for adults [18]. Little information is now available about health and social investment into child and adolescent mental well-being. However, as denounced in the Florence Declaration - developed during the 13th European Society for Child and Adolescent Psychiatry (ESCAP) Congress and signed by WHO and by EACAP (European Academy for Child and Adolescent Psychiatry) - as regards Europe, all indicators strongly suggest that child and adolescent mental health in most countries is receiving a relatively small proportion of funding, with, in turn, a typically low investment for general health, on average only $5.6 \%$ (see appendix). The median percentage of governments' health budget earmarked for mental health is as little as $1 \%$ in low income countries [19]. The gap is not limited to the quantity, as the quality of services is often extremely poor, even in high income countries [19].

Nevertheless, the mental well-being of children still remains a major public health priority and a prominent area of international debate. Scientists and researchers from all over the world are focusing on how to improve

\section{KARGER}

Fax +4161306 1234

E-Mail karger@karger.ch

www.karger.com (c) 2008 S. Karger AG, Basel

0033-3190/08/0776-0331\$24.50/0

Accessible online at:

www.karger.com/pps
Ernesto Caffo, MD

Mother and Child Department, University of Modena and Reggio Emilia

Largo del Pozzo, 71

IT-41100 Modena (Italy)

Tel. +39 059422 2106, Fax +39059422 2275, E-Mail caffo@unimo.it 
children's mental health, how to ameliorate the accessibility and the quality of services, how to strengthen the effectiveness and the efficiency of treatments, and finally how to overcome stigma and protect children's rights (see appendix). The magnitude of children and adolescent mental disorders, taken with the limited investments and availability of services, argue for preventive and early treatment interventions capable of promoting healthy development and psychological well-being $[20,21]$, both by strengthening protective factors and reducing risk factors.

In fact, even though the etiology of developmental mental disorders is multifactorial, a large number of risk and protective factors have been identified. Trauma exposure, for example, is a significant risk factor for psychiatric impairment. In a recent epidemiological study, more than two thirds of children reported at least one traumatic event by sixteen years of age, suggesting that potentially traumatic events are fairly common in childhood and adolescence [22-25]. Other well-known risk factors include parental psychopathological disorders [26], domestic violence and bullying [27, 28], physical abuse [29], having a chronic paediatric illness [30], poverty and material hardship [31,32]. Longitudinal studies have also shown that 'consistent and engaging parenting styles, parents and friends who model healthy behaviour, being in full-time education in a school with a zero-tolerance policy towards bullying and the promotion of a learning atmosphere where individual needs and interests are addressed, and involvement in community activities and religious observance are protective' [1, p 1305].

Preventive intervention should be consistent with these findings, evidence-based and possibly implemented by non-specialist health workers in primary health care settings $[1,33,34]$. However, what are the most promising examples of preventive interventions now available?

Preventive interventions have been classified as universal (targeting the entire population), selective (targeting a population at risk) and indicated (targeting subthreshold symptoms) [35]. Several reviews and metaanalyses have demonstrated that prevention programs for children and adolescents produce significant benefit by reducing the rates of future social, behavioural and academic problems [21]. Durlak and Wells [36] reviewed 177 universal prevention studies, finding significant mean effects ranging from 0.24 to 0.93 according to program type and target population. Their findings showed that preventive interventions had the dual benefits of enhancing competencies (assertiveness, communication skills, self-confidence and academic performance) and reducing internalizing and externalizing problems. One year later, the same authors found significant mean effects ( 0.50 on average) after reviewing 130 indicated prevention studies [37]. After the analysis of 130 universal, selective or indicated school-based programs, Greenberg et al. [38] concluded that multiyear programs are more likely to foster enduring benefits that short-term interventions, that the most effective programs are the ones focused on multiple domains (individual, school and family), and that the main goals of a program should be children's behaviour, teacher and family behaviour, home-school relationship and neighbourhood support for healthy, competent behaviour [39].

There is a promising universal intervention specifically designed to help children in the first years of school and to develop the necessary skills for life-long emotional well-being [40].

Others are directed at children at risk of developing specific mental disorders. Four conduct disorder preventive programs [41-44] produced significant results in randomised controlled trials. These programs are designed for children at risk in their early years (0-7 years) and use parent training or child social skills training (problem-solving skills, communication, friendshipbuilding and self-control skills).

As to mood disorder prevention programs, a significant reduction of symptomatology and new cases of anxiety and depression was obtained in school-age children (10-13 years) by using universal cognitive-behavioural training (CBT) [45]. Significant benefits of cognitive-behavioural therapy (CBT) over the no-treatment control group were found at 6 and 24 months after the intervention $[46,47]$. When parent training was combined with child group CBT, there were some additional benefits for the children [48]. Clarke et al. $[49,50]$ also used CBT in school-aged children. This intervention, which generally takes place in schools and is administered to students screened and selected from the general population, produced a significant decrease in major depressive episodes or dysthymia in the experimental condition compared to the controls. The CBT interventions included teaching children positive coping skills, such as problem solving and identifying and challenging distortions associated with the disorder.

Alleviating the negative (psychological distress) through psychological interventions is one target of efforts. Engendering the positive (through the promotion of psychological well-being) could be another way to reach the same goal, and may yield important protective 
factors in the face of future challenges and adversity [51, 52]. In this direction, a specific psychotherapeutic strategy for enhancing well-being (well-being therapy; WBT) has been developed $[53,54]$ and tested in controlled trials, both alone [53] and in addition to cognitive-behavioral packages [55-59]. The results of these studies have documented its efficacy on the adult population. A protocol for the application of WBT in a school setting has been developed. A pilot study documented its feasibility and showed a significant improvement in symptoms and psychological well-being [60]. Further controlled studies with larger samples and follow-up of children are in progress and may disclose whether WBT has a role in the prevention of psychological distress and in increasing resilience to stressful life situations.

Taken together, the evidence surveyed in this article provides a substantial foundation for prevention programs which can have strong potential as part of the spectrum of mental health interventions for children and adolescents, particularly given the large numbers of children these programs may involve. However, despite the scientific support for prevention programs and scientists' efforts to develop this area of research, most of the children in the world outside research trials still have little access to these programs. Prevention is still not a sufficiently high priority for state or federal policy makers and funders. This is mainly because of a marked separation between research and practice. Ripple and Zingler [61] provide promising data concerning the benefits of prevention policy, and proposed several steps toward filling this gap. As also highlighted by the Florence Declaration, new investments in prevention are needed. As reviewed above, effective preventive strategies already exist, others are in progress and showed promising effects at a preliminary stage [60]. Let us now forge a link between evidence-based research and practice, and give every child in the world access to these programs and the chance to fulfill his/her full potential.

\section{Appendix}

Florence Declaration: Mental Well-Being of Children in Europe: Plans and Perspectives, 13th European Society for Child and Adolescent Psychiatry Congress, Florence, Italy, August 25-29, 2007

\section{Preamble}

This Declaration was developed during the 13th European Society for Child and Adolescent Psychiatry (ESCAP) congress (Florence, Italy, August 25-29, 2007), which was attended by the lead- ing experts in the field. The conference discussed the current state of European child psychiatry, and put forward recommendations as how to improve children's mental health, how to strengthen the effectiveness and the efficiency of treatments, how to ameliorate the accessibility and the quality of services and, finally, how to overcome stigma and protect children human rights.

It is consistent with the UN Declaration of the Rights of the Child [62], the Geneva Declaration of the Rights of the Child [63], the UN Convention on the Rights of the Child [64], the WHO Mental Health Declaration For Europe [65] and Mental Health Action Plan for Europe [66], and the EC Green Paper on Mental Health [67]. By adopting these documents, Member States have committed themselves to promote the mental health of all children and adolescents, and ensure that mental health policies include as priorities the mental health and well-being of children and adolescents. Member States have committed themselves to develop and make available and accessible mental health services that are sensitive to the particular needs and human rights of children and adolescents, operating in close collaboration with families, schools, day care centres, neighbours, extended families and friends. They recognise the right of children with disabilities and/ or mental health problems to enjoy a full and respectable life, in conditions which ensure dignity, promote self-reliance and facilitate the child's active participation in the community, as well as effective protection from abuse and neglect.

Roots of Child and Adolescent Psychiatry in Europe

European child psychiatry arises from a dynamic coexistence of different theoretical models and approaches. A common basis is the culture of human rights; child and adolescent psychiatry in Europe is inspired by the deep respect of children's rights. By valuing these approaches and building on their strengths, while sharing a strong commitment to a shared value system, it is possible to develop a versatile model of child psychiatry, able to provide the means to prevent and cope with psychological and psychiatric difficulties by offering interactive and holistic interventions at community, family and individual levels. The European tradition also involves the social and public field, aiming at creating networks of many agencies which all contribute to the support of young people on the basis of their real needs only, by ignoring their age, gender, social or cultural background. In Europe, child psychiatrists respect individual differences, not only in the therapeutic realm, but also in the areas of public mental health addressing promotion and prevention. Child and adolescent psychiatry is strongly linked to other neighboring disciplines such as pediatrics, neurology, psychiatry and psychology, and to many other activities targeted at the child's physical and mental health, such as pedagogy, rehabilitation, speech therapy and physiotherapy. This interdisciplinary work is fundamental for prevention, treatment and research in the field of developmental age. The 3rd Millennium Europe wants to be more and more open to new and different cultures. Migration from neighboring as well as from more distant countries requires our systems to be more flexible in order to respond to new cultures and habits. The aim of European child psychiatry is to harmoniously integrate these populations and to enrich their cultures.

The Scale of the Problem

Europe is facing massive challenges in child and adolescent mental health. Fortunately, most people in Europe enjoy a high 
quality of life: according to the World Health Organization [12], $80 \%$ of young people report good psychological well-being. However, 1 adolescent out of 5 has cognitive, emotional and behavioral difficulties and 1 adolescent out of 8 suffers from a diagnosable mental disorder, and the prevalence is increasing decade by decade. Suicide associated with depression, substance abuse, eating disorders, conduct disorders, attention deficit hyperactivity disorders and post-traumatic stress disorder in children are all deserving concerted action. Developmental psychiatric disorders rarely have a spontaneous remission, and may cause difficult social adaptation or mental disorder in adult life if not diagnosed and treated early. Child mental health is important in its own right, but it has also to be considered in the context of a lifespan approach; most adult mental disorders find their origin in childhood and adolescence and require early intervention and treatment. Mental disorders prevented in childhood are mental disorders prevented for life.

\section{The Treatment Gap}

The availability of mental health services and the number of child psychiatrists varies widely across European countries, ranging from 1 per 5,300 people under the age of 20 to 1 per 51,800 for the same population group. Countries of the European Union strongly differ in the organization of children and adolescent mental health services and in the content and organization of child psychiatry training. Little information is available about health and social investment into child and adolescent mental well-being, but all indicators strongly suggest that child and adolescent mental health in most European countries is receiving a relatively small proportion of funding within mental health, which in turn receives a low investment from general health investment, on average only $5.6 \%$. Investing in the mental health of children and adolescents is the most cost-effective intervention, aiming at preventing the burden of mental health problems in all age groups, and lowering the personal suffering and loss of productivity at the individual, family and population levels throughout life.

\section{Developing Responses}

Recognizing the needs of children, adolescents, families and communities of Europe, and backed up by the evidence developed by European experts, the signatories of this declaration believe that European countries, regions and municipalities, supported and advised by intergovernmental agencies such as the Council of Europe, the European Commission and the World Health Organization, in partnership with NGOs including ESCAP, should all endorse the following actions that will assure the optimal mental well-being of young people:

\section{Services and Pathways to Care}

The core of our commitment is a reduction of the institutional approaches of care, which engender social exclusion. On the contrary, it is essential to improve the quality of life of people with mental problems or disability through social inclusion and the protection of their rights and dignity. The availability of services, mostly at the community-based level, helps patients and their families by providing an immediate and individualized answer to their needs. We believe that social and medical systems need to integrate their specific fields of action, with individual well-being as their central objective. This requires:
- Planning adequate community mental health services for all ages, adequately staffed by well-trained professionals working in multidisciplinary teams and integrated in primary health care.

- Developing community mental health services for the whole lifespan ensuring comprehensiveness and continuity of care, especially for the severely mentally ill, which monitors the patient's transition from child psychiatric care to adult psychiatric care.

- Monitoring and evaluating the utilization, the quality and the effectiveness of existing services.

\section{Interventions}

We want to offer effective and timely interventions, accessible to everyone on the basis of his/her need, balanced by the investment of evidence-based primary and secondary prevention by:

- Applying interventions, both preventive and therapeutic, grounded on reliable and valid evidence; research findings should be implemented in clinical practice.

- Basing good practice on a mix of skills and approaches. Singletheory approaches should be avoided.

- Creating a European-wide formulary for the use of psychopharmacological medications with children and adolescents.

\section{Prevention}

We believe that the essential first step for addressing mental ill health is prevention. Promotion of mental health and well-being relies primarily on prevention strategies, which should focus on individual, family, community and social determinants of mental health, both by strengthening protective factors (e.g. resilience) and reducing risk factors (primary prevention). This can be achieved by:

- Developing programmes in school settings, where children spend large parts of their time. Examples include school approaches targeting psychological well-being, life skills and bullying prevention.

- Identifying mothers at risk of post-natal depression through nurses' home visits.

- Teaching parenting skills to at-risk families in order to improve child development.

- Supporting anti-stigma programmes that target social awareness and support the social inclusion of the patient and his/her family.

- Allocating appropriate funding, according to the needs and resources in each country.

\section{Human Rights}

We believe that services, intervention and prevention have all to be placed within a general framework which gives primary value to the respect for human rights and for diversity, including the rights of children and adolescents. Mental health cannot be imposed. It requires:

- Planning and developing actions with the active involvement of parents or legal tutors.

- Empowering children and adolescents respecting their age and development.

- Assessing needs in a way which is sensitive to the cultural background and diversity of children, families and communities. 


\section{Training}

We believe that the training of young child psychiatrists and researchers represents a fundamental element for the growth of our discipline, and that greater partnership across Europe will benefit the quality of research and practice. Research funding should increasingly cross boundaries thereby achieving added value for Europe. We support this by:

- Achieving a greater cohesion in training goals and methods for Child and Adolescent Psychiatry in Europe as the knowledge in the field of children and adolescents mental health is constantly evolving and international activities are increasing.

- Stimulating the implementation of best practices and the application of latest scientific data by regular professional updates.

- Encouraging multi-disciplinary practice by shared training.
Research and Information

We believe that the common values of European child and adolescent psychiatry demand greater coordination of information and research, providing benefit to all participants. Experiences of one country increasingly are of value elsewhere. This requires:

- The harmonization of existing national and international indicators on child and adolescent mental health and disability, in order to create a comparable dataset across Europe.

- The stimulus of international research by committing research funding to multi-centre studies.

- The setting up of a mechanism for applying international studies to local circumstances.

Matt Muijen, World Health Organization - Regional Office for Europe

Ernesto Caffo, European Academy of Child and Adolescent Psychiatry

Eugenio Giani, Comune di Firenze

Luigi Nigi, Provincia di Firenze

\section{References}

1 Patel V, Flisher AJ, Hetrick S, McGorry P: Mental health of young people: a global public-health challenge. Lancet 2007;369:13021313.

2 WHO: Final documents of the ministerial conference Mental Health Action Plan for Europe and European Declaration on Mental Health, Helsinki 12-15 January 2005. Geneva, World Health Organization, 2005.

- 3 Weissman MM, Wolk S, Goldstein RB; Moreau D, Adams P, Greenwald S, Klier CM, Ryan ND, Dahl RE, Wickramaratne P: Depressed adolescents grown up. JAMA 1999; 281:1707-1713.

4 Kotler LA, Cohen P, Davies M, Pine DS, Walsh BT: Longitudinal relationships between childhood, adolescent, and adult eating disorders. J Am Acad Child Adolesc Psychiatry 2001;40:1434-1440.

5 Woodward LJ, Fergusson DM: Life course outcomes of young people with anxiety disorders in adolescence. J Am Acad Child Adolesc Psychiatry 2001;40:1086-1093.

-6 Harrington R, Fudge H, Rutter M, Pickels A, Hill J: Adult outcomes of childhood and adolescent depression. I. Psychiatric status. Arch Gen Psychiatry 1990;47:465-473.

7 Kazdin AE, Bass D, Ayers WA, Rodgers A: Empirical and clinical focus of child and adolescent psychotherapy research. J Consult Clin Psychol 1990;58:729-740.

$\checkmark 8$ Hofstra MB, Van der Ende J, Verhulst FC: Continuity and change of psychopathology from childhood into adulthood: a 14-year follow-up study. J Am Acad Child Adolesc Psychiatry 2000;39:850-858.

9 Remschmidt H, Schmidt MH: Disorders in child and adolescent psychiatry; in Henn F, Sartorius N, Helmchen H, Lauter H (eds): Contemporary Psychiatry, vol 2. Berlin, Springer, 2001, pp 60-116.
10 Costello EJ, Mustillo S, Erkanli A, Keeler G, Angold A: Prevalence and development of psychiatric disorders in childhood and adolescence. Arch Gen Psychiatry 2003;60:837844.

11 Costello EJ, Foley DL, Angold A: 10-year research update review: the epidemiology of child and adolescent psychiatric disorders. II. Developmental epidemiology. J Am Acad Child Adolesc Psychiatry 2006;45:8-25.

12 WHO: World health report. Geneva, World Health Organization, 2004

13 Kessler RC, Berglund P, Demler O, Jin R, Merikangas KR, Walters EE: Lifetime prevalence and age-of-onset distributions of DSMIV disorders in the National Comorbidity Survey Replication. Arch Gen Psychiatry 2005;62:593-602.

-14 Kessler RC, Ammiger GP, Aguilar-Gaxiola S, Alonso J, Lee S, Ustun TB: Age of onset of mental disorders: a review of recent literature. Curr Opin Psychiatry 2007;20:359364.

15 Scott S, Knapp M, Henderson J, Maughan B: Financial costs of social exclusion: follow-up study of antisocial children into adulthood. BMJ 2001;323:191-196.

16 WHO: Atlas child and adolescent mental health resources. Global concerns: implications for the future. Geneva, World Health Organization, 2005. http://www.who.int/mental_health/resources/Child_ado_atlas.pdf.

17 Belfer ML: Critical review of world policies for mental healthcare for children and adolescents. Curr Opin Psychiatry 2007;20:349352.

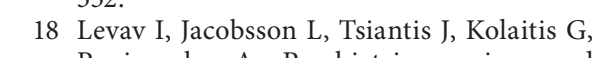
Ponizovsky A: Psychiatric services and training for children and adolescents in $\mathrm{Eu}$ rope: result of a country survey. Eur Child Adolesc Psychiatry 2004;13:395-401.
9 Saraceno B: Mental health system research is urgently needed. Int J Ment Health Syst 2007;1:2.

20 Weissberg RP, Kumpfer KL, Seligman ME: Prevention that works for children and youth: an introduction. Am Psychol 2003;58: 425-432.

21 Weisz JR, Sandler IN, Durlak JA, Anton BS: Promoting and protecting youth mental health through evidence-based prevention and treatment. Am Psychol 2005;60:628648.

22 Copeland WE, Keeler G, Angold A, Costello EJ: Traumatic events and posttraumatic stress in childhood. Arch Gen Psychiatry 2007;64:577-584

23 Caffo E, Belaise C: Violence and trauma: evidence-based assessment and intervention in children and adolescents: a systematic review; in Remschmidt $\mathrm{H}$, Nurcombe B, Belfer M, Sartorius N, Okasha A (eds): The Mental Health of Children and Adolescents: an Area of Global Neglect. Chichester, John Wiley \& Sons, 2007, pp 137-164.

24 Caffo E, Strik Lievers L, Forresi B: Child abuse and neglect: a mental health perspective; in Garralda ME, Flamant M (eds): Working with Children and Adolescents: an Evidence Based Approach to Risk and Resilience. Oxford, Aronson, an imprint of Rowmans and Littlefield Publishers, 2006, pp 95-128.

25 Caffo E, Forresi B, Strik Lievers L: Impact, psychological sequelae and management of trauma affecting children and adolescents. Curr Opin Psychiatry 2005;18:422-428.

26 Gao W, Paterson J, Abbott M, Carter S, Iusitini L: Maternal mental health and child behaviour problems at 2 years: findings from the Pacific Islands Families Study. Aust NZ J Psychiatry 2007;41:885-895. 
27 Harris WW, Lieberman AF, Marans S: In the best interests of society. J Child Psychol Psychiatry 2007;48:392-411.

-28 Arseneault L, Walsh E, Trzesniewski K, Newcombe R, Caspi A, Moffitt TE: Bullying victimization uniquely contributes to adjustment problems in young children: a nationally representative cohort study. Pediatrics 2006;118:130-138.

-29 Sprinter KW, Sheridan J, Kuo D, Carnes M: Long-term physical and mental health consequences of childhood physical abuse: results from a large population-based sample of men and women. Child Abuse Negl 2007; 31:517-530.

-30 Turkel S, Pao M: Late consequences of chronic pediatric illness. Psychiatr Clin North Am 2007:30:819-835.

- 31 Gershoff ET, Aber JL, Raver CC, Lennon MC: Income is not enough: incorporating material hardship into models of income associations with parenting and child development. Child Dev 2007;78:70-95.

- 32 Patel V, Kleinman A: Poverty and common mental disorders in developing countries. Bull World Health Organ 2003;81:609-615.

33 Belfer ML, Saxena S: WHO Child Atlas Project. Lancet 2006;367:551-552.

34 Belfer ML: Child and adolescent mental disorders: the magnitude of the problem across the globe. J Child Psychol Psychiatry 2008; 49:226-236.

-35 Gordon RS: An operational classification of disease prevention. Public Health Rep 1983; 98:107-109.

- 36 Durlak JA, Wells AM: Primary prevention mental health programs for children and adoelscents: a meta-analytic review. Am J Community Psychol 1997;25:115-152.

- 37 Durlak JA, Wells AM: Evaluation of indicated preventive intervention (secondary intervention) mental health programs for children and adolescents. Am J Community Psychol 1998;26:775-802.

38 Greenberg MT, Domitrovich C, Bumbarger $\mathrm{B}$ : The prevention of mental disorders in school-aged children: Current state of the field. Prev Treat 2001;4. http://content.apa. org/journals/pre/4/1/1a.

-39 Greenberg MT, Weissberg RP, O’Brien MU, Zins JE, Fredericks L, Resnik H, Elias MJ: Enhancing school-based prevention and youth development through coordinated social, emotional, and academic learning. Am Psychol 2003;58:466-474.

-40 Mishara BL, Ystgaard M: Effectiveness of a mental health promotion program to improve coping skills in young children: 'Zippy's Friends'. Early Child Res Q 2006;21:110123.

-41 Olds D, Henderson CR Jr, Cole R, Eckenrode J, Kitzman H, Luckey D, Pettitt L, Sidora K, Morris P, Powers J: Long-term effects of nurse home visitation on children's criminal and antisocial behavior: 15-year follow-up of a randomized controlled trial. JAMA 1998; 280:1238-1244.
42 Schweinhart LJ, Weikart DP: The High/ Scope Preschool Curriculum Comparison study through age 23. Early Child Res Q 1997;12:117-143.

43 Ialongo N, Poduska J, Werthamer L, Kellam S: The distal impact of two first-grade preventive interventions on conduct problems and disorder in early adolescence. J Emot Behav Disord 2001;9:146-160.

44 Conduct Problems Prevention Research Group: Evaluation of the first 3 years of the Fast Track prevention trial with children at high risk for adolescent conduct problems. J Abnorm Child Psychol 2002;30:19-35.

45 Lowry-Webster HM, Barrett PM, Dadds MR: A universal prevention trial of anxiety and depressive symptomatology in childhood: preliminary data from an Australian study. Behav Change 2001;18:36-50.

46 Dadds MR, Spence SH, Holland DE, Barrett PM, Laurens KR: Prevention and early intervention for anxiety disorders: a controlled trial. J Consult Clin Psychol 1997;65:627635.

47 Dadds MR, Holland DE, Laurens KR, Mullins M, Barrett PM, Spence SH: Early intervention and prevention of anxiety disorders in children: results at 2-year follow-up. J Consult Clin Psychol 1999;67:145-150.

48 Bernstein GA, Layne AE, Egan EA, Tennison DM: School-based interventions for anxious children. J Am Acad Child Adolesc Psychiatry 2005;44:1118-1127.

49 Clarke GN, Hawkins W, Murphy M, Sheeber LB, Lewinsohn PM, Seeley JR: Targeted prevention of unipolar depressive disorder in an at-risk sample of high school adolescents: a randomized trial of a group cognitive intervention. J Am Acad Child Adolesc Psychiatry 1995;34:312-321.

50 Clarke GN, Hornbrook M, Lynch F, Polen M, Gale J, Beardslee W, O'Connor E, Seeley J: A randomized trial of a group cognitive intervention for preventing depression in adolescent offspring of depressed parents. Arch Gen Psychiatry 2001;58:1127-1134.

51 Ryff CD: Happiness is everything, or is it? Exploration on the meaning of psychological well-being. J Pers Soc Psychol 1989;57:10691081.

52 Ryff CD, Singer B: Psychological well-being: meaning, measurement and implication for psychotherapy research. Psychother Psychosom 1996;65:14-23.

53 Fava GA, Rafanelli C, Cazzaro M, Conti S, Grandi S: Well-being therapy. Psychol Med 1998;28:475-480.

54 Fava GA, Ruini C: Development and characteristics of a well-being enhancing psychotherapy strategy: well-being therapy. J Behav Ther Exper Psychiatry 2003;34:45-63.

55 Fava GA, Rafanelli C, Grandi S, Conti S, Belluardo P: Prevention of recurrent depression with cognitive behavioral therapy. Arch Gen Psychiatry 1998;55:816-820.
56 Fava GA, Ruini C, Rafanelli C, Grandi S: Cognitive behavior approach to loss of clinical effect during long-term antidepressant treatment: a pilot study. Am J Psychiatry 2002;159:2094-2095.

57 Fava GA, Ruini C, Rafanelli C, Finos L, Conti S, Grandi S: Six year outcome of cognitive behavior therapy for prevention of recurrent depression. Am J Psychiatry 2004;161:18721876.

58 Fava GA, Ruini C, Rafanelli C, Finos L, Salmaso L, Mangelli L, Sirigatti S: Well-Being Therapy of generalized anxiety disorder. Psychother Psychosom 2005;74:26-30.

59 Belaise C, Fava GA, Marks IM: Alternatives to debriefing and modifications to cognitive-behavior therapy for post-traumatic stress disorder. Psychother Psychosom 2005; 74:212-217.

60 Ruini C, Belaise C, Brombin C, Caffo E, Fava GA: Well-being therapy in school settings: a pilot study. Psychother Psychosom 2006;75: 331-336.

-61 Ripple CH, Zingler E: Research, policy, and the federal role in prevention initiatives for children. Am Psychol 2003;58:482-490.

62 Declaration of the rights of the child, proclaimed by General Assembly resolution 1386(XIV) of 20 November 1959.http:// www.unhchr.ch/html/menu3/b/25.htm.

63 Geneva declaration of the rights of the child, adopted 26 September, 1924, League of $\mathrm{Na}$ tions. http://un-documents.net/gdrc1924. htm.

64 Convention on the rights of the child, UN document series symbol: ST/HR/UN issuing body: secretariat Centre for Human Rights, adopted and opened for signature, ratification and accession by General Assembly resolution $44 / 25$ of 20 November 1989, entry into force 2 September 1990, in accordance with article 49.

65 Mental health declaration for Europe. WHO European Ministerial Conference on Mental Health: Facing the Challenges, Building Solution. Helsinki, Finland, 12-15 January 2005. http://www.euro.who.int/document/ mnh/edoc06.pdf (accessed 20 December 2006)

66 Mental health action plan for Europe. WHO European Ministerial Conference on Mental Health: Facing the Challenges, Building Solution. Helsinki, Finland, 12-15 January 2005. http://www.euro.who.int/document/ mnh/edoc07.pdf (accessed 20 December 2006)

67 Improving the mental health of the population: towards a strategy on mental health for the European Union (green paper). European Commission, Health and Consumer Protection Directorate-General, Brussels, 2005, COM(2005)484. http://ec.europa.eu/health/ ph_determinants/life_style/mental/green paper/mental_gp_en.pdf (accessed 20 December 2006). 